\title{
Quality of care by neonatal nurse practitioners: a review of the Ashington experiment
}

\author{
D Hall, A R Wilkinson
}

Arch Dis Child Fetal Neonatal Ed 2005;90:F195-F200. doi: 10.1136/adc.2004.055996

The Ashington experiment, an innovative neonatal service run entirely by advanced neonatal nurse practitioners (ANNPs), has been evaluated. This is a report of that evaluation and a review of the benefits, hazards, and implications of nurse practitioner led services.

$\mathrm{N}$ ine years ago in Ashington, Northumberland, a new neonatal service was established, run entirely by advanced neonatal nurse practitioners (ANNPs) with no paediatric medical staff on site. This new model of care-the "Ashington experiment" —attracted considerable interest among professionals and policy makers. Some doctors questioned whether nurses are equipped to make diagnoses and plan treatments, while some nurses feared that nursing skills and the tradition of care would be diluted if they took on such tasks. ${ }^{1}$ We report here how the Ashington experiment has been subjected to an evaluation ${ }^{2}$ in what was perhaps the most thorough study ever undertaken of a district general hospital neonatal service. The paper then reviews the benefits, hazards, and implications of nurse practitioner led services and considers the problems inherent in assessing new models of care.

\section{HISTORY}

Ashington is an industrial town in the northeast of England with a population of 28 000. It is 17 miles north of the major city of the region, Newcastle upon Tyne, and 100 miles south of Edinburgh, Scotland. With the decline of the local mining industry over the last 15 years, Ashington has experienced a high level of unemployment and deprivation.

The hospital serves most of the residents of the rural county of Northumberland and has an annual delivery rate of about 2000 . There are five consultants in obstetrics and gynaecology. There has never been an inpatient paediatric unit; from the time the maternity unit first opened in 1967, the special care baby unit was staffed by a paediatric senior house officer (SHO), who referred any problems to a consultant paediatrician based in Newcastle. This post became progressively less acceptable for training, and was finally withdrawn in July 1996. Closure of the obstetric and newborn service would have caused considerable local distress and anger, and re-provision elsewhere for an additional 2000 births would have been very difficult. There was therefore a strong incentive to seek an alternative solution.
After extensive local and regional consultations, a team of nurses was recruited from within the existing neonatal nursing workforce, to be trained as ANNPs in the School of Nursing at the University of Northumbria in Newcastle. They then assumed responsibility for all the duties within the maternity unit involving diagnosis, treatment, admission, and discharge that are carried out by the SHOs and registrars in the 10 other level 2 units in the Northern region. ${ }^{2}$

\section{DESCRIPTION OF THE ANNP SERVICE}

The Northumberland Health Authority supported the new model of service and, as the audit of its work began to emerge, was able to show the local community that it was a substantial improvement on what had been available earlier. The Ashington service is now well supported by the public, general practitioners, the Newcastle paediatricians, local councillors, and members of parliament and this has given the ANNPs the confidence to develop their skills. It was essential to secure full cooperation, a good working relationship, and excellent communication with all members of the obstetric and midwifery team and with other hospital clinical, managerial, and service departments.

The ANNPs all work as nurses with additional skills, rather than being employed as staff in a quasi-medical role. Six ANNPs were recruited initially. The neonatal unit now functions with eight who work hours equal to 6.4 whole time staff (whole time equivalents, WTE), but this is still insufficient when an extra pair of hands is needed to deal with two simultaneous emergencies, such as the unavoidable delivery of preterm twins. Nor does it permit adequate time for ANNPs to be released for professional development, as originally envisaged. Furthermore, at present, the ANNPs operate an informal backup service so that, when help is needed, another member of the team can be called from home, but this relies on their good will, and, until recently, there were no formal remuneration or staffing arrangements for this. In view of these pressures, it is now accepted that two more WTE posts are needed. This will also give much needed support should an ANNP leave or be unexpectedly absent. Similar pressures can affect all services now that locum ANNPs or registrars are so difficult to recruit. The ANNPs themselves have long recognised the importance

Abbreviations: ANNP, advanced neonatal nurse practitioner; $\mathrm{SHO}$, senior house officer; WTE, whole time equivalents 


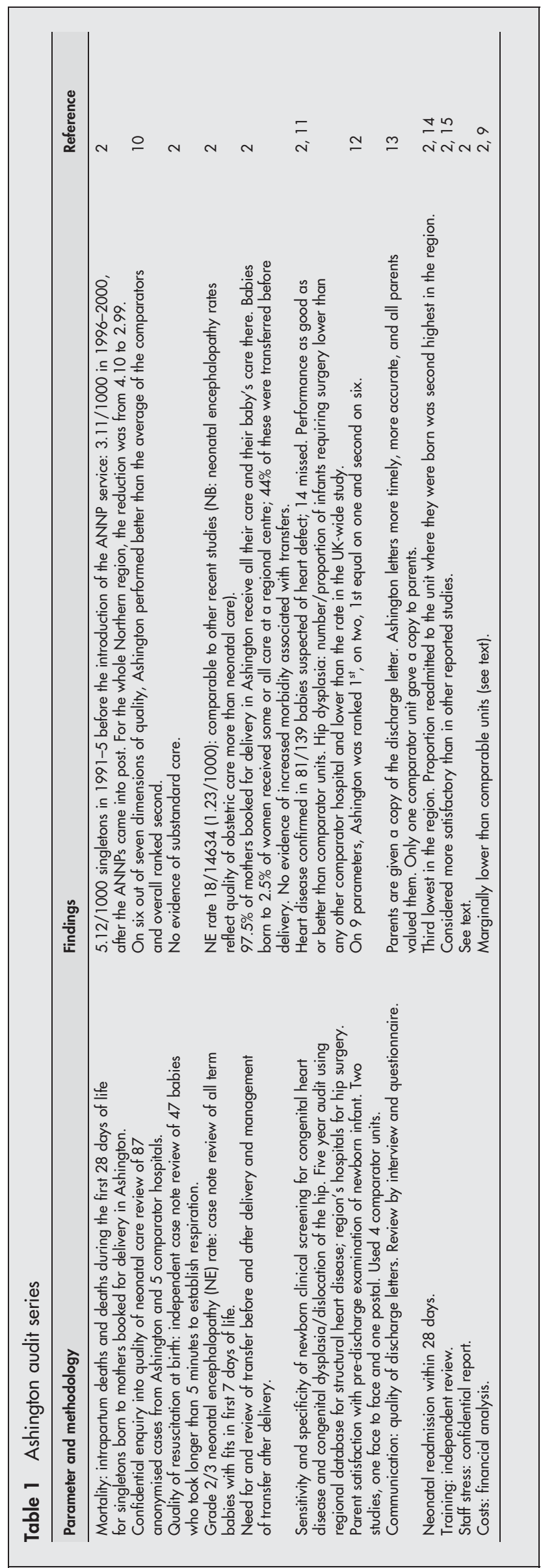

of supporting the training of the other nursing staff (10.6 WTE) who are not qualified as ANNPs.

Newly graduated nurse practitioners, like junior doctors, need support from their consultant colleagues when faced with a crisis or in the event of any serious adverse incident. ${ }^{3}$ The ANNPs attribute much of the early progress and continuing success of the Ashington unit to the early intensive input and continuing guidance of the Newcastle neonatologists. In addition to three regular consultant follow up clinics per month in the Ashington neonatal unit, one of the neonatology consultant team visits the unit at least once a week and more often if necessary. This support enables the ANNPs to continue developing their competence and confidence. In common with other similar units in the Northern region, the obstetric team has a policy that mothers presenting in labour before 31-32 weeks gestation should be transferred to a tertiary unit, provided that this is judged to be safe and the labour is not far advanced. The obstetric team will transfer the care of mothers with high risk pregnancies for either maternal or fetal reasons (or both). Otherwise babies requiring special or high dependency care can be looked after at Ashington. The regional retrieval service based in Newcastle transfers babies for further medical or surgical care. Ashington receives no greater priority for this than any other unit in the Northern Region, although a member of the retrieval team will always try to arrive quickly to help with the ongoing stabilisation if the baby is extremely immature. One of the ANNPs visits the Newcastle hospital twice a year to tell newly appointed trainee paediatricians how the Ashington unit functions.

\section{THE NEED FOR EVALUATION}

The public and policy makers want to know whether this model of care is as good, as safe, and as acceptable to the users as that offered by the conventional structure, based on a rota of junior doctors resident in the hospital and backed up by a readily available consultant on call. How can quality be measured and what comparisons would be appropriate? Does the ANNPs' training prepare them adequately for the job? If so, what factors contribute to safety and quality? Can such a service be sustained? Can it be generalised to other parts of the United Kingdom and elsewhere and, if so, what is needed to make this possible?

Attempts to measure safety and quality of clinical care, even in very large comparative studies within or between countries, ${ }^{45}$ are fraught with difficulty. Differences in case mix and local population characteristics, coupled with random variability, make it almost impossible to undertake useful comparisons between death rates. ${ }^{6}$ Only gross differences in performance between neonatal units are likely to achieve statistical significance in less than three years. The lack of comprehensive national follow up data make morbidity figures, for example disability rates or uncommon conditions missed by newborn screening, ${ }^{7}$ even less useful. A literature search failed to reveal either any comprehensive review of a district neonatal service or any validated mechanism by which this could be achieved. Routine data collection did not appear to offer any simple outcome measures, performance standards, audit processes, or financial data by which the care at Ashington could be compared with conventional models of newborn care. Furthermore, while parents share the commitment of professionals to technical excellence in health care, they also greatly value local access, compassionate care, and good communication, and no evaluation would be complete if these were ignored.

A thorough multifaceted evaluation was therefore undertaken by a multidisciplinary team composed of a local steering group and an external expert advisory panel. The team enlisted the help of five comparator units and used the 
high quality epidemiological child health data collected in the Northern Region. The measures were intended to tap technical expertise, care, and communication, and the staff and financial aspects of the service. The variables studied included perinatal mortality figures, early encephalopathy rates, and a review of sentinel events, using a modification of the well established confidential enquiry process. ${ }^{8}$

Table 1 summarises the various studies and the results. On a wide range of measures, the Ashington unit appears to be providing care that is at least as good as other units of comparable size staffed by doctors. The figures for mortality and for neonatal encephalopathy, and the audits and confidential enquiries offer no evidence that technical excellence has suffered as a result of having no doctor on site. The routine examination and care of the newborn are undertaken to a high standard, as measured both by detection of key disorders such as heart disease or hip disorders, and by parental satisfaction. The very low staff turnover and the continued commitment of the nurses, supporting consultants, and managers to the service show that sustainability is no longer in question.

The Ashington service was not introduced as a cost saving exercise, but in 1998-1999 the costs at Ashington were marginally $(7 \%)$ less than the mean annual running cost of the 18 units with below average consultant cover who only cared for a small number of very low birthweight babies, described in the recent national neonatal staffing study.

\section{COMPARISONS WITH OTHER STUDIES}

A literature search produced many descriptive papers on new nursing roles in a range of disciplines, a smaller number of formal comparisons between doctors and nurses in paediatric settings, and a systematic review of comparisons between nurse practitioners or midwives and doctors, ${ }^{16}$ but no systematic review of such comparisons in neonatology or paediatrics was identified. Most published comparisons between doctors and ANNPs have in common the following characteristics: they compare doctors of resident or trainee status with nurses undertaking advanced practitioner roles for which they have received formal training; they use a small number of outcome measures; they are conducted within a single centre; they deal with neonatal or paediatric intensive care; they emanate from North America or the United Kingdom, with none identified from other EU member states, even when no language exclusion is placed in the search parameters. More descriptive papers were published in nursing journals than in medical paediatric journals, but most formal comparisons were found in paediatric journals, so it is unlikely that there is a publication bias in favour of studies that show nurses performing better than doctors.

Table 2 summarises 12 reports ${ }^{17-28}$ in the fields of neonatal and paediatric intensive care (excluding those from Ashington). In five studies, there were no differences of substance between ANNPs and residents. In seven, the differences, although mainly small, favoured ANNPs.

\section{IS THE ASHINGTON MODEL SUSTAINABLE?}

Changing from a traditional newborn service based on resident doctors, to one run by ANNPs, is neither cheap nor easy. After eight years it is clear that the change can be achieved without major local political turmoil and that the model is sustainable-in Ashington. But is it transferable to other places and is it sustainable over a longer period of time?

Career development is the norm for high calibre health professionals, and some ANNPs may want to acquire experience in a variety of environments-for example, in a tertiary level unit, or in education or management. Because of economic and geographic factors, the stability of the Ashington nursing team may be greater than might be the case in other places. There is no obvious further career progression for the nurses in Ashington, but this does not currently appear to be an issue and, in general, the nurses are satisfied with their jobs. They enjoy the level of responsibility it provides and the opportunity to provide continuity of care for babies, and support for parents. The nurse manager is a full member of the ANNP team and this has helped maintain good rapport and stability in the face of organisational and management changes in the NHS. Being solely responsible for the care of babies, including resuscitation, without any on site paediatric presence, is as responsible and stressful a job as that of a middle grade junior doctor and deserves comparable remuneration. The ANNPs work a standard 37.5 hour week, and their average basic salary (in 2004) is about $£ 31$ 000; SHOs in comparison work 48 hours for a similar average salary, and Specialist Registrars earn about $20 \%$ more.

The stability of the ANNP team is not unique to Ashington. A survey of ANNPs trained in the Southampton programme ${ }^{29}$ showed that most were still in the original unit from which they had been seconded for training, and around three quarters were still working as ANNPs 5-10 years later. Factors involved in their job satisfaction included a well defined role, working within a team of ANNPs, appropriate remuneration, and evidence of support for both role definition and continuing professional development. Attitudes of other professionals are important. ${ }^{30}$ Nurse practitioners should be seen as an alternative approach to high quality service provision and not as a substitute for resident doctors or a way of delegating tasks that doctors find boring.

\section{OBSTACLES TO GENERALISING THE ASHINGTON MODEL}

There are a number of obstacles to generalising this model in the short term. Firstly, training courses for ANNPs each have their own particular philosophy and aims, developed in collaboration with the hospitals for which they provide training opportunities, so that the title ANNP may not imply precisely the same array of expertise in every unit. There are benefits in encouraging local innovation and ownership in ANNP course development, but it is also important to ensure that these nurses have formal recognition of their specialised transferable skills, which would in the long run make these posts more attractive. ${ }^{15}$ Clarification of the legislation and guidance on nurse prescribing would simplify both practice and standardisation of training. New nursing roles will only fulfil their potential when the relevant regulatory authorities address and clarify these issues. ${ }^{31}$

A second obstacle is the national shortage of nurses. Perhaps the kind of career progression made possible by these new roles will attract more recruits into nursing, although where children's nursing is concerned the shortage is in training places rather than in recruits.

The third difficulty is the cost of training an advanced practitioner-not only the course fees but also the need to fill that post while the nurse is attending the course. This is compounded by the anxiety that other trusts will then "poach" the newly trained advanced practitioner by offers of a more attractive package - a problem that could be addressed in various ways but would eventually be overcome if more ANNPs are trained.

\section{IMPLICATIONS OF THE ASHINGTON EXPERIMENT}

The evidence gathered in Ashington suggests that a nurse led unit can provide a high standard of care for newborn infants. This finding is in keeping with the published literature both from the United Kingdom and North America and has implications for addressing the problems created by the 


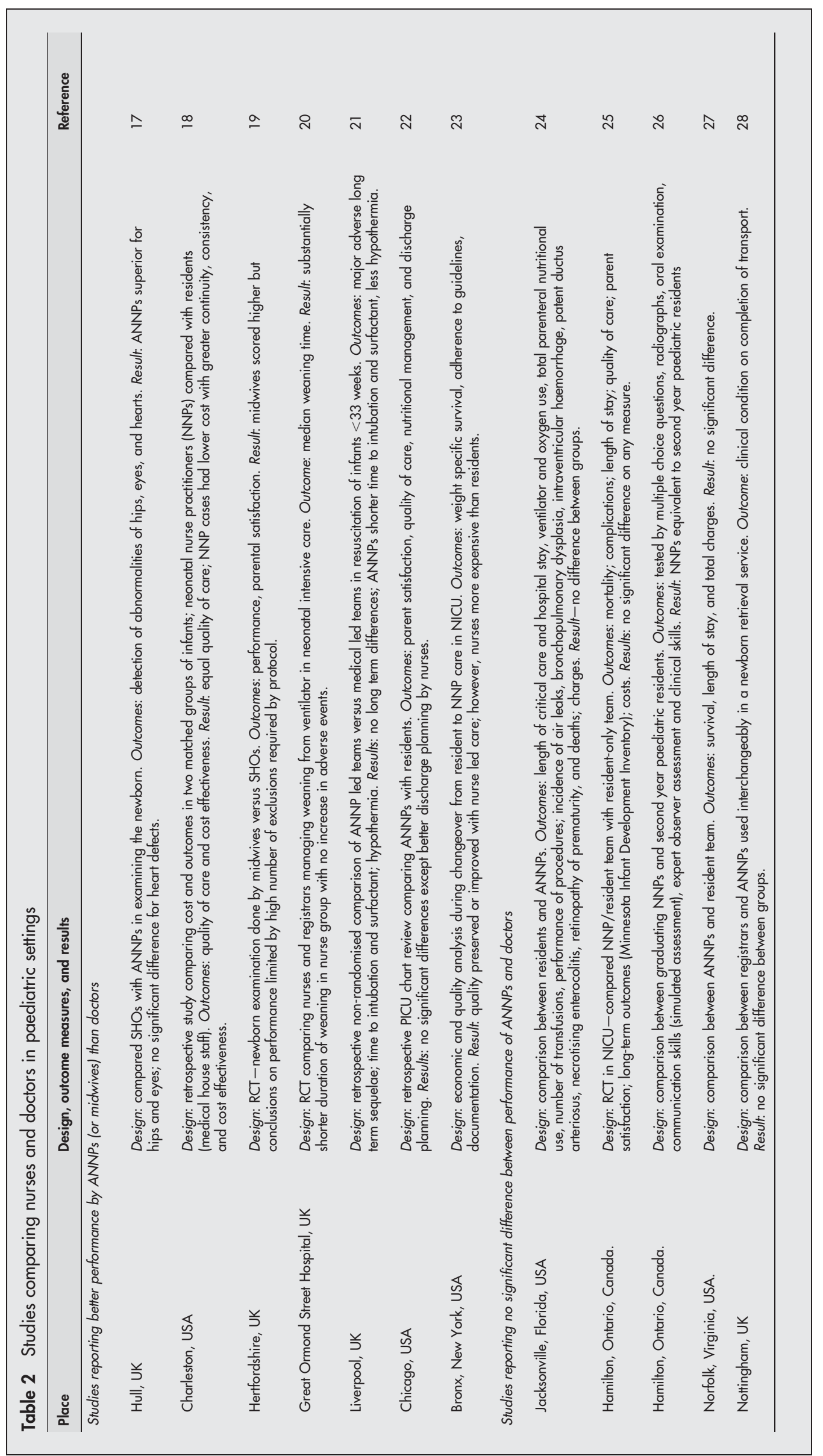


worldwide shortage of health professionals. The need to limit working hours and the difficulty of maintaining skills when patient turnover is low make it increasingly difficult to staff small maternity and neonatal units in the traditional way. Professional advice usually favours the concentration of services in large units, as this permits subspecialisation, allows development of a critical mass for research, and makes optimum use of expensive scarce medical staff. ${ }^{32}$ However, the public perception is different. People feel more comfortable in the familiar surroundings of a local hospital. Travel to and attendance at an unfamiliar hospital in a big city are intimidating to those who rarely leave their home town, and the close proximity of relatives and their other children are reassuring. These considerations put pressure on politicians and planners to find ways of sustaining services in smaller departments.

If shortage of doctors forces the closure of small maternity and newborn units, the workload would transfer to a smaller number of large units, but there is no guarantee that the nurses would transfer as well. More efficient use of medical staff might be counterbalanced by an increased nursing shortage. The Ashington model offers a solution to this dilemma, without compromising the safety and quality of the care provided.

An ANNP led model might also have benefits in large units: it would offer additional career development opportunities for nurses, cut the number of specialist registrars required to maintain a rota, and reduce the amount of time that consultant neonatologists spend resident on call. There would be important implications for future workforce planning, both for doctors and for paediatric nurses.

At first glance it may seem surprising that nurses performed as well as, or better than, resident doctors. The comparisons may be unfair. Nurses are selected to train as advanced practitioners after several years of intensive hands on experience, and they undertake a formal period of study, with clear learning objectives and assessment tasks and a period of mentoring. Junior doctors take up posts as part of a training rotation in which previous experience of neonatal care may be rudimentary. Perhaps it is not surprising that they do not perform as well in straightforward comparisons, although their broader basic science background may give them the advantage when it comes to analytical reasoning in a complex problem. Clearly, these observations prompt questions about the optimal staffing of intensive care units and the ways in which doctors are trained, both for routine tasks like examining the newborn and in the highly technical environment of neonatal and paediatric intensive care.

The United Kingdom has been slow to adopt and develop the nurse practitioner role. After some early scepticism, ${ }^{33} 34$ the concept of ANNPs is widely accepted in North America and its relevance to the United Kingdom's perennial shortage of middle grade paediatricians was highlighted in a $B M J$ leader almost 30 years ago. ${ }^{35}$ The paucity of reports from most other member states of the European Union is perhaps less surprising, as in other healthcare systems ANNPs may be perceived as a threat to doctors' incomes.

Why has there been a particular focus on nurse practitioner roles in neonatal and paediatric intensive care units? The reasons may include the attraction and challenge of this work for nurses; the concentration of care in time and place, making it easier to monitor; a high level of protocol based decision making derived from a solid research base and measurable physiological variables; and the intensity of the teamwork that results in a high level of mutual trust and respect. It has been argued that acute general paediatrics would be a more difficult area in which to develop advanced practitioner roles, but the relatively small number of conditions that account for the bulk of paediatric medical accident and emergency attendances, ${ }^{36}$ together with several studies comparing nurses and doctors in adult accident and emergency departments and in acute general medicine, suggest that this too may be an unduly pessimistic view.

The evaluation of the Ashington project was difficult in spite of the excellent epidemiological data available in the Northern Region. Many of the comparisons required time consuming ad hoc studies. A standard dataset that captures neonatal and follow up data is urgently needed so that, in future, models of care, standards of practice, and the reasons for differences between units can be evaluated more efficiently and with greater precision.

In summary, the Ashington experience has shown that ANNPs can provide a high standard of neonatal care without a doctor on site; it has established the conditions needed for a successful introduction of this model of care; it has highlighted the difficulties in measuring quality of care (a lesson that undoubtedly applies to other aspects of health care as well as neonatology); and it has presented a challenge to the health professions to create and test innovative ways of sustaining services that otherwise might have to be closed.

\section{ACKNOWLEDGEMENTS}

The evaluation was a team effort involving the full participation of the Ashington ANNPs. The members of the external steering group (listed by the Ashington Audit Group[2]) played a vital role in ensuring objectivity in the evaluation. In particular, we thank: Dr Helen Watson, Consultant in Public Health Medicine who recognised the importance of evaluating the project; Dr Unni Wariyar, who "adopted" the Ashington unit and supported it throughout; Dr Ed Hey, for his enthusiasm and commitment to the project and for extensive data analysis.

\section{Authors' affiliations}

D Hall, Institute of General Practice, ScHARR, University of Sheffield, Northern General Hospital, Sheffield S5 7AU, UK

A R Wilkinson, Department of Paediatrics, University of Oxford, John Radcliffe Hospital, Oxford OX3 9DU, UK;

andrew.wilkinson@paediatrics.ox.ac.uk

Competing interests: none declared

The guarantor is $\mathrm{DH}$.

\section{REFERENCES}

1 Dowling S, Barrett S, West R. With nurse practitioners, who needs house officers? BMJ 1995;311:309-13.

2 Ashington Audit Group. Evaluating a nurse-led model for providing neonatal care. J Adv Nurs 2004;47:39-48.

3 Redshaw M, Harvey M. Students' experiences on neonatal nurse practitioner programmes. Br J Nurs 2001;10:1120-6.

4 Field D, Hodges S, Mason E, et al. Survival and place of delivery. Arch Dis Child 1991;66:408-11.

5 International Neonatal Network SNCNCSG. Risk adjusted and population based studies of the outcome for high risk infants in Scotland and Australia. Arch Dis Child Fetal Neonatal Ed 2000;82:F118-23.

6 Field D, Manktelow B, Draper E. Bench marking and performance management in neonatal care: easier said than done. Arch Dis Child Fetal Neonatal Ed 2002;87:F163-4.

7 Elliman D, Dezateux C, Bedford H. Newborn and childhood screening programmes: criteria, evidence and current policy. Arch Dis Child 2002;87:6-9.

8 CESDI. Confidential enquiry into stillbirth and deaths in infancy: 8th annual report. London: Maternal and Child Health Research Consortium, 2001.

9 The UK Neonatal Staffing Study Group. Patient volume, staffing, and workload in relation to risk-adjusted outcomes in a random stratified sample of UK neonatal intensive care units: a prospective evaluation. Lancet 2002;359:99-107.

10 Ward Platt MP, Brown K. Evaluation of advanced neonatal nurse practitioners: confidential enquiry into the management of sentinel cases. Arch Dis Child Fetal Neonatal Ed 2004;89:F241-4.

11 Godward S, Dezateux C. Surgery for congenital dislocation of the hip in the UK as a measure of the outcome of screening. Lancet 1998;351:1149-52.

12 Northumberland Community Health Council. The pre-discharge examination of normal newborn babies in Northumberland. Morpeth, Northumberland CHC, 2003.

13 Northumberland Community Health Council. Neonatal nurse practitioner survey: parents' views of the discharge letter. Morpeth, Northumberland CHC in association with Northumberland Health Authority, 1998. 
14 Oddie S, Hammal D, Richmond S, et al. Early discharge and readmission to hospital in the first month of life in the Northern Region of the United Kingdom during 1998: a case cohort study. Arch Dis Child 2005;90:119-24.

15 Redshaw M, Harvey M. Education for a new role: a review of neonatal nurse practitioner programmes. Nurse Educ Today 2001;21:468-76.

16 Brown S, Grimes D. A meta-analysis of nurse practitioners and nurse midwives in primary care. Nurs Res 1995;44:332-9.

17 Lee TW, Skelton RE, Skene C. Routine neonatal examination: effectiveness of trainee paediatrician compared with advanced neonatal nurse practitioner. Arch Dis Child Fetal Neonatal Ed 2001;85:F100-4.

18 Bissinger RL, Allred CA, Arford PH, et al. A cost-effectiveness analysis of neonatal nurse practitioners. Nurs Econ 1997;15:92-9.

19 Wolke D, Dave S, Hayes J, et al. Routine examination of the newborn and maternal satisfaction: a randomised controlled trial. Arch Dis Child Fetal Neonatal Ed 2002;86:F155-60.

20 Luyt KB. Compared with specialist registrars, experienced staff nurses shorten the duration of weaning neonates from mechanical ventilation. Pediatr Crit Care Med 2002;3:351-4.

21 Aubrey WR, Yoxall CW. Evaluation of the role of the neonatal nurse practitioner in resuscitation of preterm infants at birth. Arch Dis Child Fetal Neonatal Ed 2001;85:F96-9.

22 Martin SA. The pediatric critical care nurse practitioner: evolution and impact Pediatr Nurs 1999;25:505-10.

23 Schulman $M$, Lucchese KR, Sullivan AC. Transition from house staff to nonphysicians as neonatal intensive care providers: cost, impact on revenue, and quality of care. Am J Perinatol 1995;12:442-6.

24 Carzoli RP, Martinez CM, Cuevas LL, et al. Comparison of neonatal nurse practitioners, physician assistants, and residents in the neonatal intensive care unit. Arch Pediatr Adolesc Med 1994; 148:1271-6.

25 Mitchell-DiCenso A, Guyatt G, Marrin M, et al. A controlled trial of nurse practitioners in neonatal intensive care. Pediatrics 1996;98:1143-8.
26 Mitchell A, Watts J, Whyte R, et al. Evaluation of graduating neonatal nurse practitioners. Pediatrics 1991;88:789-94.

27 Karlowicz MG, McMurray JL. Comparison of neonatal nurse practitioners' and pediatric residents' care of extremely low-birth-weight infants. Arch Pediatr Adolesc Med 2000;154:1123-6.

28 Leslie A, Stephenson T. Neonatal transfers by advanced neonatal nurse practitioners and paediatric registrars. Arch Dis Child Fetal Neonatal Ed 2003;88:F509-12.

29 Smith SL, Hall MA. Developing a neonatal workforce: role evolution and retention of advanced neonatal nurse practitioners. Arch Dis Child Fetal Neonatal Ed 2003;88:F426-9.

30 Nicolson P, Burr J, Powell J. Becoming an advanced practitioner in neonatal nursing: a psycho-social study of the relationship between educational preparation and role development. J Clin Nurs 2005:14:1-13.

31 Chief nursing officer. Post registration development: a framework for planning, commissioning and delivering learning beyond registration for nurses and midwives. The report of a task group convened and chaired by the Chief Nursing Officer, 2004. London: Department of Health, www.dh.gov.uk/ Consultations/ClosedConsultations/ClosedConsultationsArticle/ $\mathrm{fs}_{\text {s }}$ / en?CONTENT_ID = 4094619\&chk= NDJSyN (accessed 2 Mar 2005).

32 Dowie R, Gravelle H. Changes in medical training and sub-specialisation: implications for service delviery. In: Ferguson B, Sheldon T, Posnett J, eds. Concentration and choice in healthcare. London: Pearson Professional, 1997:51-65

33 Cassady G. Through the looking glass-or, look before you leap. Pediatrics 1982;70:1001-3

34 Harper RG, Little GA, Sia CG. The scope of nursing practice in level III neonatal intensive care units. Pediatrics 1982;70:875-8.

35 Anonymous. Neonatal nurse practitioners. BMJ 1975;1:115-16.

36 Arnon K, Stephenson T, Gabriel V, et al. Determining the common medical presenting problems to an accident and emergency department. Arch Dis Child 2001;84:390-2. 